E3S Web of Conferences 1, 10008 (2013)

DOI: $10.1051 / \mathrm{e} 3$ sconf/20130110008

(c) Owned by the authors, published by EDP Sciences, 2013

\title{
Leaching behaviour of mercury from hazardous solid waste generated by chlor-alkali industry
}

\author{
Y. Busto ${ }^{1,2}$, F. M. G. Tack ${ }^{2}$ and X. Cabrera ${ }^{1}$ \\ ${ }^{1}$ Departamento de Ingeniería Química, Facultad de Química y Farmacia, Universidad Central "Marta Abreu" de las \\ Villas, C. Camajuaní km. 51ㄹ, Santa Clara, Cuba, yailenb09@gmail.com \\ ${ }^{2}$ Laboratory for Analytical Chemistry and Applied Ecochemistry, Bioengineering Science Faculty. Ghent University, \\ Coupure Links 653, B-9000, Ghent, Belgium, filip.tack@ugent.be \\ ${ }^{3}$ Departamento de Ingeniería Química, Facultad de Química y Farmacia, Universidad Central "Marta Abreu" de las \\ Villas, C. Camajuaní km. 51ㄹ, Santa Clara, Cuba, xiomyc@gmail.com
}

\begin{abstract}
Through the conventional chlor-alkali production process, highly mercury (Hg) contaminated waste sludge is produced. Improper handling and disposal of this sludge may cause an environmental hazard. The leaching behaviour of $\mathrm{Hg}$ of land disposed mercurial sludge, originating from a chlor-alkali plant that still is in operation, was investigated using the German DIN 38414-S4 test. The total mercury content of the samples was above $1500 \mathrm{mg} / \mathrm{kg}$, allowing the material to be classified as hazardous and high mercury waste. Concentrations of $\mathrm{Hg}$ in the leachates were higher than $0.02 \mathrm{mg} / 1$ stipulated by the 1991 EEC Landfill Directive Draft as a maximum limit for a waste that is to be landfilled. Total Hg contents and leachability differed markedly between the samples, pointing to a heterogeneity in the production of the sludge. The more limited release of $\mathrm{Hg}$ from one of the samples might reflect an ageing effect, or might reflect a better quality of the stabilization process at the time of production. Results indicate that the approach used to stabilize the sludge has not been sufficiently effective, and warrant caution about existing disposal sites and future management of these mercury containing waste materials.
\end{abstract}

Key words: Mercury - Hazardous mercury waste - Chlor-alkali process - Heavy metal mobility - Leaching test

\section{Introduction}

Mercury-cell chlor-alkali plants (MCCaP) produce chlorine and caustic soda by electrolysis of brine, using mercury as the cathode. In this process, large quantities of mercury are handled. Although this process is based on 19th century technology, MCCaPs around the world still account for roughly $15 \%$ of the global mercury demand, and are a significant source of local and global mercury pollution (Biester et al, 2002; Ulrich et al., 2007). This process is not anymore considered good industrial practice and is increasingly being replaced by more environmentally friendly technologies such as those involving the use of diaphragm and membranes cells (Mukherjee et al., 2004).

In Cuba, the production of chlorine and caustic soda started in the mid 1930's. Thousands of tons of mercurial sludge are currently stored in the surroundings of the plant, constituting a possible hazard to human health and environment.

The mercury containing solid wastes in the Cuban factory are generated after mixing the exhausted mercury of the electrolytic cell with sodium sulphide in a first step, and with sodium chloride, calcium carbonate, magnesium hydroxide and diatomaceous earth in a second step. Contact of the sludge with ground water or rain may cause mercury to leach and contaminate the soil and underground water. In the present work, the DIN S4leaching test was used to assess mercury release from this contaminated sludge. The main objective of this study is to evaluate the actual environmental risk that this mercurial sludge represents.

\section{Materials and Methods}

Two samples of mercurial waste sludge were collected from two different storage niches on the disposal site. Sample 1 had been more than one year in the niche whereas Sample 2 was disposed four months before sampling. Each sample was prepared as a composite sample from equal amounts of sludge taken from three different points on a diagonal line. Samples were air- 
dried for seven days, hand-crushed in a mortar, and passed through a $2 \mathrm{~mm}$ sieve.

Sample properties such as $\mathrm{pH}$, electrical conductivity, organic matter content and carbonate content were determined using standard procedured (Van Ranst et al., 1999). Total mercury content was determined by cold vapour atomic absorption spectrometry (Mercury Analyzer MAS-50, Coleman, Oak Brook, Illinois, USA) after a specific destruction as reported by Cottenie (1982).

Leachability of $\mathrm{Hg}$ from the mercurial sludge was assessed using the DIN 38414-S4 leaching test (DIN 38414-S4, 1984). After determination of $\mathrm{pH}$ and electrical conductivity the leachate samples was acidified to a $\mathrm{pH}$ below 2 with concentrated $\mathrm{HNO}_{3}$ to store the sample before analysis. All extractions were carried out in triplicate. Total concentration of $\mathrm{Hg}$ in the leachates was determined using cold vapour atomic absorption spectrometry (Mercury Analyzer MAS-50, Coleman, Oak Brook, Illinois, USA).

\section{Results and Discussion}

The mercurial sludge contained up to $70 \%$ carbonates and exhibited an alkaline $\mathrm{pH}$ of $9.3-9.4$. This is caused by the presence of calcium carbonate and magnesium hydroxide, two components added during the stabilisation of the waste product. Also diatomaceous earth, which is used at a rate of $300 \mathrm{~g}$ per $\mathrm{kg}$ sludge, contributes carbonate to the final waste product. Elevated chloride levels, in the order of $50 \mathrm{~g} / \mathrm{kg}$, result from the brine, which is the raw material used for the production of chlorine and sodium hydroxide.

Between the two samples, mercury total contents differed by a factor of three, pointing to a marked variability in the production of mercurial sludge. In both samples, mercury concentrations were much higher than $260 \mathrm{mg} \mathrm{Hg} / \mathrm{kg}$, allowing the materials to be classified as hazardous high mercury wastes according to US EPA: LDR (USEPA, 2008).

The DIN S4 leaching test provides indications on the release of elements when the contaminated material is contacted with increasing amounts of leaching agent. High $\mathrm{pH}$ values of the leachates, at 9.5 and higher, resulted from the presence of free hydroxides provided by the $\mathrm{Mg}(\mathrm{OH})_{2}$ used during the preparation of the sludge. High values of electrical conductivity in the first fraction $(19 \mathrm{dS} / \mathrm{m})$ revealed the presence of significant amounts of soluble salts.

The concentrations of $\mathrm{Hg}$ in the fractions of the DIN test differed greatly, by more than one order of magnitude, between both samples (Fig. 1). Overall, Hg concentrations decreased in subsequent fractions of the DIN leaching test, although Sample 2 exhibited a pronounced increase, by a factor of three, in mercury concentration in the second fraction compared to the first. It is difficult to explain the different behaviour between sludge samples considering that chemical characteristics were similar. As Sample 1 was one year older, the more limited release of $\mathrm{Hg}$ from that sample, despite its higher total $\mathrm{Hg}$ content (5600 for Sample 1 versus 1500 for Sample 2) might be attributed to an ageing effect. However, it might also reveal a significant variability in the quality of stabilization applied to the sludge. Regular sampling and testing of the produced sludge would be required to ascertain the variability in the production.

The Council Directive 91/689/EEC on hazardous waste establishes when a waste can be considered a "hazardous waste" and defines limit concentration values for each hazardous constituent and the applicable test methods (EC, 1991). The limit value for mercury concentration in the leachate of DIN38414-S4 fractions is $0.02 \mathrm{mg} / \mathrm{l}$ (Bayar et al., 2009). The mercury concentrations in all fractions of both samples strongly exceeded this permissible limit (Fig. 1). Although Sample 1 showed a much slower release of $\mathrm{Hg}$, the concentrations values in all fractions were still hundredfold above the permissible limit.

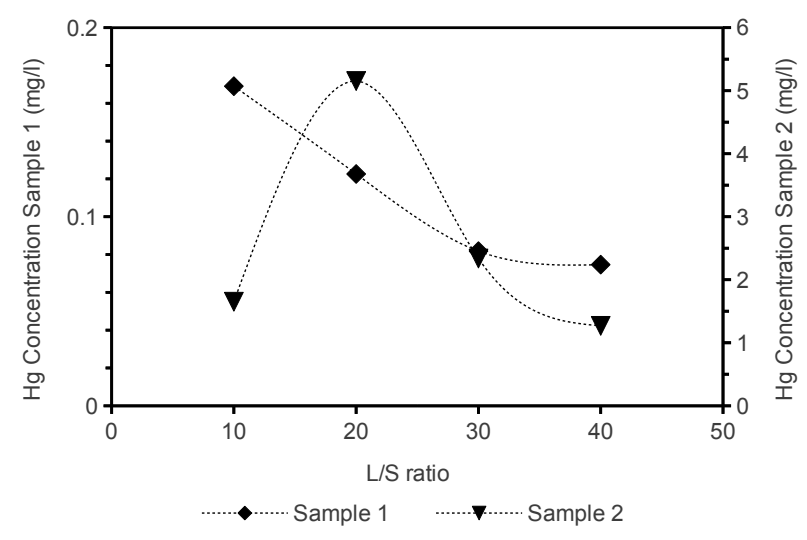

Fig. 1. Mercury concentration in the DIN S4 leaching test fractions at increasing liquid to solid ratio (L/S ratio) for two samples of mercurial sludge samples. Note different scales for each of the samples.

The leaching test data clearly show that the current treatment of the mercury waste is not sufficiently effective to stabilize the mercury. Long term leaching and migration of contaminants from improperly disposed wastes can result in contamination of both surface and ground water.

The high concentrations of $\mathrm{Hg}$ in the DIN test fractions, especially for Sample 2, indicate the presence of more soluble mercury forms. $\mathrm{HgCl}_{2}$ has a practical solubility in water of $70 \mathrm{~g} / \mathrm{l}$. However, also the solubility of sulphidic mercury forms may be higher than expected by the extremely low solubility constants of the compounds, considering the high $\mathrm{pH}$ of the mercurial sludge. At high $\mathrm{pH}$, an increased solubility of $\mathrm{HgS}$ results from the formation of polysulphide mercury forms such as $\mathrm{HgS}_{2}{ }^{2-}$ and $\mathrm{Hg}\left(\mathrm{S}_{\mathrm{x}}\right)_{2}{ }^{2-}$ (with $\mathrm{x}=3-6$ ) (Paquette and Helz, 1997). In addition, oxidation of mercury sulphides during the leaching process may contribute to enhance mercury mobility (Holley et al., 2007).

Historical disposal sites may not meet the strict 
requirements needed to guarantee safe storage of this highly hazardous waste material. Remedial action may involve treatment of the sludge to remove the mercury or to reduce the leachability to acceptable levels. Alternatively, the material may need to be disposed in tightly sealed and thoroughly controlled dedicated disposal sites. Better techniques to stabilize the generated mercurial sludge may also contribute toward a safe handling and storage of the waste. More research on long term leaching, mercury speciation and treatment technologies is needed to develop adequate strategies to manage this waste.

\section{Conclusion}

Results of the leaching test clearly indicate that the stabilization process applied to the mercurial sludge did not allow to prevent significant leaching of mercury. The sludge may therefore be stored only in tightly sealed conditions. Fortunately, the trend to shift towards other, non mercury based technologies will decrease and eventually eliminate the production of this mercurial waste sludge.

\section{Acknowledgements}

This study was supported by the Belgian Programme for Institutional University Co-operation (VLIR -UCLV). Project \# 7: "Environmental Education and Cleaner Technologies".

\section{References}

Bayar S, Demir I, Onkal GE. Modelling leaching behaviour of solidified wastes using backpropagation neural networks. Ecotox Environ Safe 2009; 72:843-850.

Biester H, Muller G, Scholer HF. Estimating distribution and retention of mercury in three different soils contaminated by emissions from chlor-alkali plants: part I. Sci Total Environ 2002; 284:177-189.

Cottenie A, Verloo MG, Kiekens E, Velghe G, Camerlynk R. Chemical analysis of plant and soil. IWONL, Brussels, Belgium, 1982.

EC. Council Directive 91/689/EEC of 12 December 1991 on hazardous waste. 1991; Available from: http://eur-lex.europa.eu/LexUriServ/LexUriServ.do ?uri=CELEX:31991L0689:EN:HTML

DIN 38414-S4. Schlamm und Sedimente, Bestimmung der Eluierbarkeit mit Wasser. DIN Deutches Institut Für Normung, Berlin, 1984.

Holley EA, McQuillan AJ, Craw D, Kim JP, Sander SG. Mercury mobilization by oxidative dissolution of cinnabar $(\alpha-\mathrm{HgS})$ and metacinnabar $(\beta-\mathrm{HgS})$. Chem Geol 2007; 240:313-325.

Mukherjee AB, Zevenhoven R, Brodersen J, Hylander LD, Bhattacharya P. Mercury in waste in the European Union: sources, disposal methods and risks, Resour Conserv Recy 2004; 42:155-182.

Paquette KE, Helz GR, Inorganic Speciation of mercury in sulfidic waters: the importance of zero-valent sulfur. Environ Sci Technol 1997; 31:2148-2153.

Ulrich S, Ilyushchenko M, Kamberov I, Tanton $T$. Mercury contamination in the vicinity of a derelict chlor-alkali plant. Part I: sediment and water contamination of Lake Balkyldak and the River Irtysh, Sci Total Environ 2007; 381:1-16.

USEPA. Land Disposal Restrictions Regulations for Mercury-Containing Non-wastewaters. R 40 CFR Part 273, 2008. Last updated, August 19, 2008. Revision date, June 10, 2010. Available from: http://www.epa.gov/epawaste/hazard/tsd/mercury/tr eatmnt.htm.

Van Ranst E, Verloo MG, Demeyer A, Pauwels JM. Manual for the Soil Chemistry and Fertility Laboratory. Ghent University, Faculty for Agricultural and Applied Biological Sciences, Ghent, Belgium, 1999. 